\title{
Macrosomic Newborn and Glucose Level in Lean Pregnant Diabetes Mellitus Patients at Dr. Soetomo General Hospital Surabaya
}

\author{
Sonea Venugopal, ${ }^{1}$ Hermanto Tri Joewono, ${ }^{2}$ Pudji Lestari ${ }^{3}$ \\ ${ }^{1}$ Faculty of Medicine Universitas Airlangga Surabaya, Indonesia, ${ }^{2}$ Department of Obstetrics \& \\ Gynaecology Faculty of Medicine Universitas Airlangga/Dr. Soetomo General Hospital Surabaya, \\ Indonesia ${ }^{3}$ Department of Public Health Faculty of Medicine Universitas Airlangga Surabaya, \\ Indonesia
}

\section{Abstract}

Background: Gestational diabetes mellitus, defined as glucose intolerance in variable degree with onset during pregnancy, is a risk factor for the development of fetal macrosomia, a newborn with the birthweight of more than $4000 \mathrm{~g}$. The objective of this study was to explore an association between glucose level in lean pregnant diabetes mellitus patients, resulting in babies and the incidence of macrosomia in Dr Soetomo General Hospital in Surabaya.

Methods: This was a retroprospective analytic study with a cross sectional design by using medical records at Dr. Soetomo General Hospital Surabaya, collected from January 2016 to December 2017. The correlation between fasting glucose level, 2-hour postprandial glucose and glucose level at the time of birth and weight of newborn was assessed.

Results: Controlled and uncontrolled fasting glucose level, 2-hour postprandial glucose level and glucose level at the time of birth of mother were not significantly associated with macrosomia newborns. Macrosomia newborn were born with gestational diabetes mellitus mothers compare with pregestational mellitus mothers.

Conclusions: There is no association between macrosomia with glucose level of lean gestational and pregestational diabetes mellitus, however, therapeutic approach such as physical exercise should be implemented to reduce effects of uncontrolled glucose level.

Keywords: Gestational diabetes mellitus, macrosomia, glucose level

\section{Introduction}

Newborn macrosomia, a newborn with the birthweight of more than $4000 \mathrm{~g}$ has a high percentage in Indonesia, that has reached $6.4 \% .^{1}$ Gestational diabetes mellitus (GDM), defined as glucose intolerance in variable degree with onset during pregnancy, is a risk factor for the development of fetal macrosomia, There are more than 150,000 cases of GDM in Indonesia with the prevalence ranging from 1.9 to $3.6 \%$ across the country.

Pregnancies, that are closely linked to diabetes, poor blood sugar control, may cause complications for the mother and child being born. Even according to research results conducted by the health research institute Confidential Inquiry into Maternal and Child Health (CEMACH), although mother blood sugar levels has been controlled, a baby still has risk of complications. Newborn by mother diabetics has risk of 5 times greater for death, would have birth defect risk of 2 times larger, and can be born with weights of more than 4000 grams or greater. ${ }^{2}$

Several studies have been conducted on risk factors of macrosomia, however, information and study in macrosomia complications are scarce. ${ }^{3}$ Fetal macrosomia may result in complications such as shoulder dystocia, birth asphyxia, nerve injuries, clavicular and humerus fractures in neonates, leading to admission to the intensive-care nursery and an increased of perinatal mortality for the newborn. Furthermore, vaginal and perineal trauma, uterine rupture, postpartum infection and hemorrhage to the mother may occur.4 Therefore, this study was conducted to identify the relationship between macrosomia and glucose level during pregnancy. Result of this study is expected to assess the importance of glycemic control to decrease the incidence of newborn macrosomia.

Correspondence: Sonea Venugopal, Faculty of Medicine Universitas Airlangga, Jl. Professor Dr. Mustopo No.47, Pacar Kembang, Jawa Timur, Indonesia, Email: soneavenugopal96@hotmail.com 


\section{Methods}

This was an analytic retrospective cross sectional study, conducted after obtaining approval from the Health Research Ethics Committee of the Faculty of Medicine, Universitas Airlangga/Dr. Soetomo General Hospital, Surabaya. A total data on newborns from medical record from the year 2016 to 2017 medical record data of newborns at the delivery room of Obstetrics and Gynaecology Department were collected. The inclusion criteria were data of women who had gestational and pre-gestational diabetes mellitus aged 21-35 years old with a normal pre-pregnancy body mass index of lower than
25 and had a complete medical data of glucose level. Data on women who had a history of smoking or still smoke as well as previous history of pregnancy complications other than diabetes mellitus were excluded from this study.

The measurement of fasting plasma glucose (FPG) level, 2 hour postprandial (2HPP) and glucose at the time of birth were categorised based on Glycemic Targets in Pregnancy by American Diabetes Association (ADA) year 2016 guidelines..$^{5}$ Glycemic status was designated as controlled with FPG $\leq 95 \mathrm{mg} / \mathrm{dL}$, $2 \mathrm{hPP} \leq 120 \mathrm{mg} / \mathrm{dL}$ and glucose at the time of birth $\leq 120 \mathrm{mg} / \mathrm{dL}$. The results were analysed using Fisher's exact test to assess statistical

Table 1 Clinical Characteristic among Gestational and Pregestational Diabetes Women with Controlled and Uncontrolled Fasting Plasma Glucose Level at Dr. Soetomo General Hospital, Surabaya from January 2016 to December 2017

\begin{tabular}{|c|c|c|c|c|}
\hline & \multicolumn{2}{|c|}{ Fasting plasma glucose level } & \multirow{3}{*}{$\begin{array}{l}\text { Total } \\
\text { N(\%) }\end{array}$} & \multirow{3}{*}{ p-value* } \\
\hline & $\begin{array}{c}\text { Controlled } \\
(\leq 95 \mathrm{mg} / \mathrm{dL})\end{array}$ & $\begin{array}{l}\text { Uncontrolled } \\
(>95 \mathrm{mg} / \mathrm{dL})\end{array}$ & & \\
\hline & $\mathbf{n}(\%)$ & n(\%) & & \\
\hline \multicolumn{5}{|l|}{ Age (years) } \\
\hline 31-35 & $9(69.2)$ & $13(65)$ & $22(66.7)$ & 0.714 \\
\hline $26-30$ & $4(30.8)$ & $6(30)$ & $10(30.3)$ & \\
\hline $21-24$ & - & $1(5)$ & $1(3)$ & \\
\hline \multicolumn{5}{|l|}{ Parity } \\
\hline Nullipara & $4(30.8)$ & $4(20)$ & $8(24.2)$ & 0.681 \\
\hline Multipara & $9(69.2)$ & $16(80)$ & $25(75.8)$ & \\
\hline \multicolumn{5}{|c|}{ Mode of delivery } \\
\hline Caesarean & $10(76.9)$ & $16(80)$ & $26(78.8)$ & 1.000 \\
\hline Vaginal & $3(23.1)$ & $4(20)$ & $7(21.2)$ & \\
\hline Total & $13(39.4)$ & $20(60.6)$ & $33(100)$ & \\
\hline
\end{tabular}

Note: *Fisher's exact test

Table 2 Fasting Plasma Glucose Level among Gestational and Pre-gestational Diabetes Women and Macrosomia State in Newborn in Delivery Room of Dr. Soetomo General Hospital, Surabaya from January 2016 to December 2017.

\begin{tabular}{lccc}
\hline & \multicolumn{2}{c}{ State in newborn } & \\
\cline { 2 - 3 } & $\begin{array}{c}\text { Non-macrosomia } \\
\mathbf{n}(\%)\end{array}$ & $\begin{array}{c}\text { Macrosomia } \\
\mathbf{n ~ ( \% )}\end{array}$ & p-value* \\
\hline Controlled & $13(100 \%)$ & - & 0.508 \\
Uncontrolled & $18(90 \%)$ & $2(10 \%)$ & \\
Total & $31(93.9 \%)$ & $2(6.1 \%)$ & \\
\hline
\end{tabular}


Table 3 Two-hour Postprandial Glucose Level among Gestational and Pregestational Diabete Women and Macrosomia State in Newborn in Delivery Room of Dr. Soetomo General Hospital, Surabaya from January 2016 to December 2017.

\begin{tabular}{|c|c|c|c|}
\hline \multirow[b]{2}{*}{$\begin{array}{c}\text { 2-hour Postprandial Glucose } \\
\text { Level }\end{array}$} & \multicolumn{2}{|c|}{ State in newborn } & \multirow[b]{2}{*}{ p-value* } \\
\hline & $\begin{array}{c}\text { Non-macrosomia } \\
\text { n (\%) }\end{array}$ & $\begin{array}{c}\text { Macrosomia } \\
\text { n (\%) }\end{array}$ & \\
\hline Controlled & $7(100 \%)$ & - & 1.000 \\
\hline Uncontrolled & $24(92.3 \%)$ & $2(7.7 \%)$ & \\
\hline Total & 31 (93.9\%) & $2(6.1 \%)$ & \\
\hline
\end{tabular}

*Note: Fisher's exact test

Table 4 Glucose Level at Birth among Gestational and Pregestational Diabetes Women and Macrosomia State in Newborn in Delivery Room of Dr. Soetomo General Hospital, Surabaya from January 2016 to December 2017

\begin{tabular}{lccc}
\hline \multirow{2}{*}{ Glucose Level at Birth } & \multicolumn{2}{c}{ State in newborn } & \\
\cline { 2 - 3 } & $\begin{array}{c}\text { Non-macrosomia } \\
\text { n (\%) }\end{array}$ & $\begin{array}{c}\text { Macrosomia } \\
\mathbf{n ~ ( \% )}\end{array}$ & p-value* \\
\hline Controlled & $15(93.8 \%)$ & $1(6.3 \%)$ & 1.000 \\
Uncontrolled & $16(94.1 \%)$ & $1(5.9 \%)$ & \\
Total & $31(93.9 \%)$ & $2(6.1 \%)$ & \\
\hline *Note: Fisher's & & & \\
\hline
\end{tabular}

*Note: Fisher's exact test

Table 5 Diabetes State among Pregnant Women with Newborn Macrosomia in Delivery Room of Dr. Soetomo General Hospital, Surabaya from January 2016 to December 2017

\begin{tabular}{lccc}
\hline & Non-macrosomia & Macrosomia & p-value \\
\hline Gestational & $\mathbf{n ~ ( \% )}$ & $\mathbf{n}(\%)$ & 1.000 \\
Pregestational & $22(70.97)$ & $2(6.45)$ & \\
Total & $9(29)$ & - & \\
\hline
\end{tabular}

*Note: Fisher's exact test

significance. A p-value $<0.05$ was considered statistically significant.

\section{Results}

In total, there were 33 data of pregnant women with poor glycemic control. Glycemic status was more likely to be poorly controlled among older patients, multipara patients and caesarean delivery was mode of delivery (Table 1).

\section{Discussions}

This study has assessed the association between uncontrolled and controlled glucose level in lean gestational and pregestational diabetes mellitus women, resulting in birth of newborns with macrosomia. Uncontrolled blood glucose levels has been found in majority of the patients, and older age of pregnant women (31-35 years old) tends to have more uncontrolled glucose level, although no significant association between age and glycemic control. This result is in contrast to other study that showed that younger patients had more uncontrolled glucose level. ${ }^{6}$ In line with the study among Chinese women in Singapore ${ }^{7}$, our result showed that the majority of uncontrolled glucose level was among multipara women, however, no statistically significant association of parity with uncontrolled glucose level has been found in this research. More than half of patients $(78.8 \%)$ with gestational and pregestational 
diabetes underwent caesarean section, as delivery need to be well planeed. ${ }^{8}$ Again, no significant association can be erected between fasting and postprandial glycemia with increased caesarean rates as shown in other study among urban women in Sri Lanka. ${ }^{9}$

The prevalence of newborn macrosomia among women with uncontrolled glucose level is $6.1 \%$, similar to other study, yet there no association between glucose control in pregnancy. ${ }^{10}$ In contrast to a general thought of a significant association between glucose control and macrosomia newborn. ${ }^{11}$ Moreover, study showed that pregestational diabetic mellitus patients is significantly associated to small birth weight and appropriate birthweight newborn. ${ }^{12}$

The limited number of pregestational and gestational women over two year period is an obstacle in this study. Therefore, further research on larger population is needed. In addition, this research has analysed fasting plasma glucose level and 2-hour postprandial glucose level within two weeks of birth as well as glucose at the time of birth to identify uncontrolled and controlled glucose level. However, this data does not represent glucose control for the whole duration of pregnancy. A better glicemic state such as HbA1c may serve as a good indicator for this study.

In conclusion, no association between fasting plasma glucose, 2-hour postprandial glucose and glucose at the time of birth of lean gestational and pregestational diabetes mellitus patients and macrosomic newborn have been found.

\section{References}

1. Purnamasari D, Waspadji S, Adam J, Rudijanto A, Tahapary D. Indonesian Clinical Practice Guidelines for Diabetes in Pregnancy. Journal of the ASEAN Federation of Endocrine Societies, 2013;28(1):9-13.

2. Cyganek K. Risk of macrosomia remains glucose-dependent in a cohort of women with pregestational type 1 diabetes and good glycemic control. Endocrine 2017;55(2):447-55.

3. Najafian M, Cheraghi M. Occurrence of fetal macrosomia rate and its maternal and neonatal complications: a 5-year cohort study. ISRN Obstet Gynecol. 2012;2012:353791.

4. Guy MM, Yves II, Charles KM, Didier MN, Sandra YM, NgoyAurelie KK, et al. Effect of gestational diabetes mellitus on macrosomia infants. Int J Cur Res Rev. 2017; 9(4):41-5.

5. American College of Obstetricians and Gynecologists' Committee on Practice Bulletins-Obstetrics. Practice Bulletin No 173: fetal macrosomia. Obstet Gynecol. 2016; 128(5):e195-e209.

6. Gopinath B, Prasad SM, Jayarama N, Prabhakara K. Study of factors associated with poor glycemic control in Type2 Diabetic patients. Global Journal of Medicine and Public Health. 2013;2(2):15.

7. Mueller NT, Mueller NJ, Odegaard AO, Gross MD, Koh WP, Yuan GM, et al. Higher parity is associated with an increased risk of type-II diabetes in Chinese women: the Singapore Chinese Health Study. BJOG. 2013;120(12):1483-9.

8. Nadir S, Jamil S, Hamid M. The prevalence of macrosomia in newborns and its association with maternal diabetes. J Med Sci.2015;23(1):3-6.

9. Eslamian L, Akbari S, Marsoosi V, Jamal A. Effect of different maternal metabolic characteristics on fetal growth in women with gestational diabetes mellitus. Iran J Reprod Med. 2013; 11(4):325-34.

10. Bianchi C, de Gennaro G, Romano M, Aragona M, Battini L, Del Prato S, et al. Pre-pregnancy obesity, gestational diabetes or gestational weight gain: which is the strongest predictor of pregnancy outcomes? Diabetes Res Clin Pract. 2018;144:286-93.

11. Ma X, Zhang T. The effect of blood glucose control on pregnancy outcomes in pregnant women with gestational diabetes mellitus. Int J Clin Exp Med. 2017;10(11):15510-5.

12. Kanda E, Matsuda Y, Makido Y, Matsui H. Risk factors associated with altered fetal growth in patients with pregestational diabetes mellitus. J Matern Fetal Neonatal Med. 2012; 25(8):1390-4. 